\title{
Entre categorias: rádio música de John Cage
}

Vera Terra*

RESUMO: O texto aborda as peças compostas por John Cage na década de 50, nas quais utilizou o rádio como material sonoro, fundamentando sua análise nos escritos e entrevistas do compositor. A utilização do rádio nessas obras é apresentada como um meio de redefinição das categorias convencionais da música e convite a uma invenção permanente. As peças radiofônicas de Cage propõem processos originais de pensar e fazer música, inaugurando a radioarte e uma forma inovadora de performance: o happening. Através delas, Cage vai construindo aquelas que constituirão as categorias fundamentais de sua poética: o silêncio concebido como os sons do ambiente, a indeterminação e a interpenetração..

PALVRAS-CHAVE: música experimental, radioarte, John Cage

ABSTRACT: The issue focuses on the pieces composed by John Cage during the fifties, in which he used radio as sound material, basing its analysis upon composer's writings and interviews. The use of radio in these works is shown as a means of redefining conventional musical categories and encouraging permanent inventiveness. Cage's radio pieces offer original processes of thinking of and composing music, giving birth to radio art and an innovative form of performance: the happening. By these works, Cage has gradually conceived those that would become the basic categories of his poetics: silence meant as ambient sounds, indeterminacy and interpenetration.

KEYWORDS: experimental music, radio art, John Cage

\footnotetext{
*Vera Terra é pianista e compositora, pesquisadora nas áreas de música e estética. Mestre em Comunicação e Semiótica (PUCSP). Integrou o concerto realizado por John Cage no Rio de Janeiro, em 1985. Publicou artigos em revistas de arte e o livro Acaso e aleatório na música: um estudo da indeterminação nas poéticas de Cage e Boulez (SP: EDUC/FAPESP, 2000). Foi co-curadora da exposição Begin anywhere: um século de John Cage, realizada em maio de 2012 no MAM-RJ, em comemoração ao centenário de nascimento do compositor. Coordena o Laboratório de Encenação e Multimídia da Faculdade Angel Vianna.
} 
Na década de 50, John Cage compôs uma série de peças nas quais utilizou o rádio como material sonoro. A primeira delas, Imaginary Landscape $n^{\circ}$ 4, foi concebida para 12 rádios e 24 intérpretes, dois atuando em cada um dos aparelhos, um movimentando o sintonizador de estações (tuner), o outro modulando a amplitude e o timbre durante a transmissão.

A obra não só é importante por utilizar de modo pioneiro emissões radiofônicas como fonte sonora, mas também por marcar uma mudança nos métodos de composição empregados por John Cage.

Imaginary Landscape $n^{\circ} 4$ situa- se, assim, na trajetória de John Cage, no início de um percurso, descrito por ele na conferência Composition As Process, proferida em Darmstadt, em setembro de 1958, que se caracteriza por um afastamento progressivo das idéias de ordem em direção à noção de indeterminação.
"Ainda há gráficos em Imaginary Landscape Número IV e em Williams Mix, mas, devido aos rádios da primeira peça e à coletânea de sons gravados da segunda, e unicamente por essa razão, nenhum controle dodecafônico foi utilizado." (CAGE, 1973, p.26) $^{1}$

“... há uma tendência em meus meios de composição ao afastamento das idéias de ordem em direção à ausência de idéias de ordem." (CAGE, 1973, p.20) 
Com relação às mudanças ocorridas neste percurso, a peça para doze rádios é apontada por Cage, em sua conferência, como um momento de ruptura em relação à questão do timbre.

\footnotetext{
"Mas, em relação ao timbre, que é em grande parte uma questão de gosto, a primeira mudança radical se deu para mim em Imaginary Landscape Número IV." (CAGE, 1973, p.30)
}

Visando libertar-se de seus gostos pessoais (likes and dislikes), para que os sons fossem apreciados em suas características próprias, como sons e não como veículos de ideias ou sentimentos, Cage concebeu a peça exclusivamente para sons gerados por rádios. A obra abriu seus ouvidos para estes sons, que até então não despertavam seu interesse.

"Há e haverá sempre sons para serem ouvidos, se houver ouvidos para ouvir; pode-se demonstrá-lo." (CAGE, 1973, p.23) ${ }^{2}$

De que material é feita a música, nos perguntamos ao ouvir Imaginary Landscape $n^{\circ} 4$ ? De sons e silêncios, dirá Cage, entendendo por silêncio os sons que não fazem parte de uma intenção musical. De tudo que soa.

\section{cisum sdnuos}

"A natureza destes [sons ambientais] é imprevisível e mutante." (CAGE, 1973, p.22) 
Ao abrigar sons radiofônicos no interior de sua obra, Cage concebe uma estrutura que não é determinada pelos materiais que a constituem, ao contrário das estruturas baseadas na freqüência dos sons, próprias ao sistema tonal. Cria estruturas rítmicas, baseadas em relações numéricas. Cage as escolhe por se mostrarem hospitaleiras a todos os tipos de sons, sejam eles musicais, de altura definida, sejam ruídos, oscilações instáveis, aperiódicas. São estruturas-tempo, estruturas-espaço, o que permite que elas se expressem tanto por meio dos materiais, quanto por sua ausência.

A peça é construída exclusivamente sobre relações de espaço. Ela se configura como uma tessitura-paisagem, como o título sugere: um espaço-tempo no interior do qual se movem, de modo imprevisível, os sons originários de 12 rádios. Vestígio da estruturação em doze sons do método dodecafônico?

\section{A noção de música como paisagem se esboça, até se radicalizar em 4'33", um campo de indeterminação pura.}

Conta-se que, por ocasião da estreia de Imaginary Landscape $n^{\circ} 4$, em 2 de maio de 1951, na Universidade de Columbia, o manuseio do botão sintonizador (tuner) encontrou muitas emissoras fora do ar, o que fez com que a tessitura da música se configurasse como um longo silêncio entrecortado por sons.

\footnotetext{
“Minhas obras recentes (Imaginary Landscape No. IV para doze rádios e Music of Changes para piano) são estruturalmente similares às obras anteriores. (...) No entanto, anteriormente as estruturas definiam durações de tempo, enquanto que nas obras recentes há apenas extensões no espaço, sendo imprevisível a velocidade das trajetórias através desse espaço." (CAGE, 1973, p. 57)
} 
"Quando eu ouço o que chamamos de música, tenho a impressão de que alguém está falando, e falando sobre seus sentimentos ou sobre suas ideias de relacionamento. Mas, quando eu ouço o som do tráfego aqui na $6^{\text {a }}$ Avenida, por exemplo, não tenho a sensação de que alguém esteja falando. Tenho a sensação de que um som está em atividade e eu adoro a atividade do som. O que ele faz é ficar mais alto e mais baixo, ficar mais agudo e mais grave, ficar mais longo e mais breve. Todas essas coisas que ele faz me satisfazem plenamente; eu não necessito de que alguém fale comigo."

"As pessoas esperam que a escuta seja algo além da escuta.

$E$ assim às vezes elas falam da escuta interior ou do significado dos sons. Quando eu falo de música, estou falando de sons que não querem dizer nada. Não é interior, mas exterior. $E$ aí as pessoas perguntam: você quer dizer que são somente sons?, como se ser apenas um som fosse algo inútil. Eu gosto dos sons assim como eles são. Eu não tenho nenhuma necessidade de que eles sejam mais do que eles são."

\section{(อ) ๒ )}

"A experiência do som que eu prefiro acima de todas as outras é a experiência do silêncio. E o silêncio, hoje, em quase toda parte do mundo, é o tráfego. Se você ouve Beethoven ou Mozart, você percebe que eles são sempre o mesmo. Mas, se você ouve o tráfego, você percebe que é sempre diferente." 3 
Em 1952, um ano após sua criação, Cage apresenta uma versão de Imaginary Landscape No.4 em um evento realizado em Black Mountain College, reunindo um grupo de artistas ligados a ele: David Tudor tocando piano preparado, Robert Rauschenberg fazendo a difusão de discos antigos, Merce Cuninngham e bailarinos de sua companhia de dança interagindo no espaço com seus movimentos, M.C. Richards lendo seus poemas. Em torno, fixadas nas paredes, as telas brancas (White Paintings) de Robert Rauschenberg. Os sons radiofônicos de Imaginary Landscape $n^{\circ} 4$ constituem, assim, o campo [espaço-tempo] no qual se interpenetram imagens, movimentos corporais, poesia e pintura, configurando uma assemblage de materiais e linguagens. O rádio está presente na experiência pioneira que dá origem ao happening.

No mesmo ano, Cage compôs Water Music, uma peça para um pianista que se utiliza também de um rádio, de apitos, recipientes com água, um baralho, uma baqueta de madeira e objetos para preparar o piano. A peça explora mais uma vez o campo da performance.

\author{
“Uma interpenetração \\ de fenômenos distintos, \\ preservados em sua \\ identidade, brotava \\ incontestavelmente \\ desse gênero de evento; \\ nenhuma hierarquia \\ se impunha entre os \\ elementos, visuais e \\ sonoros, destinados a se \\ encontrar fugazmente, no \\ espaço de um instante." \\ (BOSSEUR, 1993, p. 39)
}

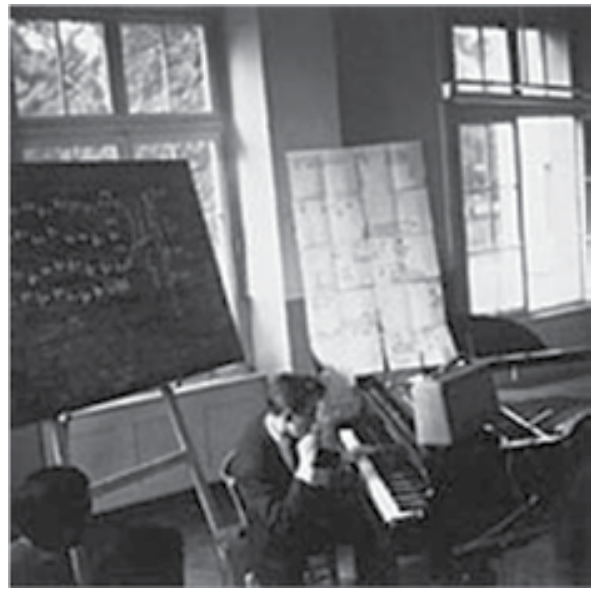

David Tudor interpretando Water Music em Darmstadt, $1958{ }^{4}$ 


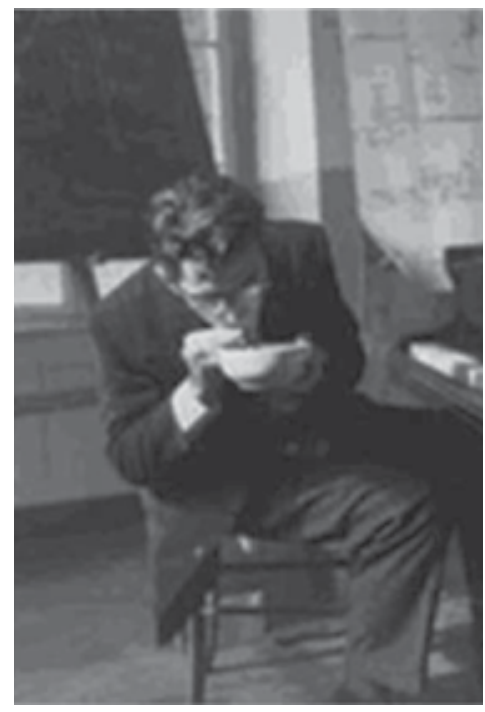

Pio para chamar patos soprado em vasilha com água (David Tudor, Darmstadt, 1958).
O que faz um pianista dotado de uma técnica apurada, construída durante anos de formação, quando tem diante de si uma partitura como a de Water Music?

Expande sua imaginação sonora (sound imagination), responderia David Tudor, intérprete próximo a Cage, que estreou várias de suas obras para piano. Experimenta novas formas de produzir sons no corpo do instrumento, inserindo pequenos objetos, como parafusos e borrachas, entre suas cordas (piano preparado), ou friccionando as cordas com os dedos, ou percutindo sobre o tampo de madeira. Faz interagir os sons do piano com outras fontes sonoras, como o rádio, pios e a água.

\section{“Water Music é uma afirmação da antiga convicção de Cage na sinonímia entre arte, vida e teatro". (TAN, 2002, Addendum 10)}

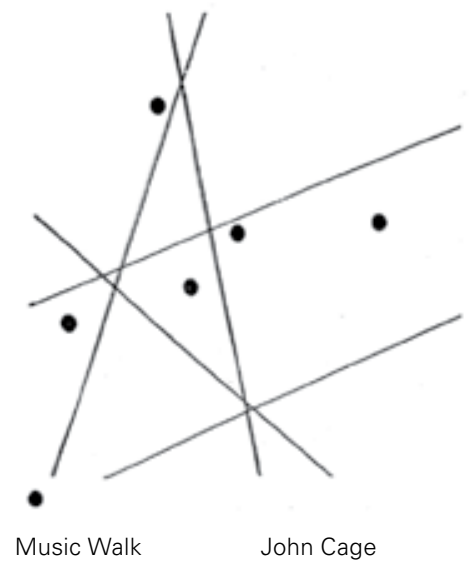

Se a partitura de Water Music ainda conserva signos da notação musical tradicional, em peças posteriores, como Music Walk, de 1958, para um ou mais pianistas que se utilizam também de sons de rádio e de fontes sonoras auxiliares, a partitura é constituída exclusivamente de pontos no espaço, sobre os quais se sobrepõem grupos de cinco linhas traçadas em transparências, que indicam o modo de produção dos sons: nas cordas, no teclado, na caixa de ressonância, no rádio, com a voz, com a preparação 
do piano ou a emissão de ruídos. A obra não tem duração definida. A indeterminação se estende a todas as dimensões da música. Não é possível prever como a peça irá se configurar, até que ela seja tocada.

Cage associa o uso da indeterminação, ao selecionar os materiais de suas músicas, a ações cotidianas. Compara a escolha dos sons das Sonatas e Interlúdios para piano preparado à coleta de conchas ao longo de uma praia. No entanto, ressalta que essa escolha ainda reflete um gosto pessoal. Na peça Speech Radio 5, para cinco rádios e um narrador, Cage aproxima a ação dos intérpretes do ato de pescar.

Muitas são as formas de coleta de materiais, concebidas não só metaforicamente. Há muito onde e o que colher. Em Fontana Mix, realizada em 1960, Cage recolhe fragmentos de fitas magnéticas abandonadas no estúdio eletrônico da rádio de Milão (RAI), espécie de "lixo musical" com o qual compõe sua obra eletroacústica.
Não procurem por nada em torno, Cage instrui os intérpretes. "Durante seus silêncios, movam [o tuner] para um ponto que vocês não tenham idéia do que seja, entendem? Então, peguem aquilo que vocês tiverem "pescado", por assim dizer." 5 
Cage gravou, ele próprio, sons ambientais na Irlanda, onde se passa a ação de Finnegans Wake. Foi auxiliado por pessoas que se dispuseram a gravar sons nos locais onde não pode ir. EnviouIhes estas instruções: "As gravações devem durar no mínimo trinta segundos e não mais que alguns minutos. Os sons não devem ser escolhidos. Simplesmente vá ao local indicado e faça uma gravação de qualquer som que você encontre quando chegar." (CAGE, 1992, Livro 1, p. 69) Cage contou ainda com a colaboração de rádios de todo o mundo, que lhe facultaram o acesso a seus arquivos de sons.

como uma peça radiofônica (Hörspiel) de uma hora de duração ${ }^{7}$, a coleta de materiais é ampla, incluindo os sons mencionados por James Joyce em seu livro Finnegans Wake e a captação $\checkmark$ de sons ambientais em vários dos lugares descritos na obra ${ }^{9}$, além de música tradicional irlandesa.

$\lambda$

Roaratorio é concebido por Cage como um circo, por não

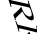
haver na obra nenhum centro, mas uma pluralidade de centros, como na vida. Ao contrário de um oratório, que se passa no interior da igreja, Roaratorio se passa do lado de fora, no mundo.

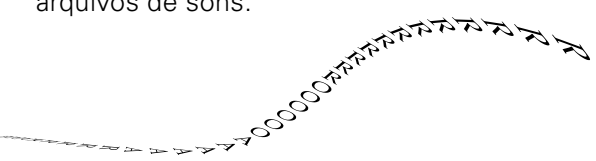

"Trata-se de um mundo feito de sons, de texto e música, em que o ouvinte pode fruir à vontade sons que ele habitualmente não tem a oportunidade de ouvir nas emissões radiofônicas, geralmente restritas à transmissão da informação unidimensional." 6 (CAGE, 1992, Livro 1, p. 2)

Os sons captados se sobrepõem sem se mesclar, gravados em 62 canais, de modo a preservar suas características particulares. Esse catálogo de sons é colado à entoação dos mesósticos criados por Cage com o nome de James Joyce a partir da leitura do $W_{a k e}{ }^{10}$, observando a localização na página e na linha onde aparecem na obra. O circo, com a música tradicional irlandesa, é colado de modo independente.

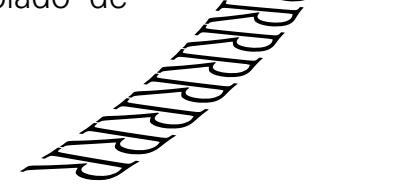


Roaratorio configura a tessitura de uma paisagem sonora constituída de ruídos, de sons ambientais não intencionais, como indica a aglutinação do verbo "roar" à palavra oratório. Nesse sentido, a obra retoma a primeira peça radiofônica realizada por Cage, em 1942, junto com o poeta Kenneth Patchen, intitulada The City Wears a Slouch Hat.

No entanto, Cage reconhece não haver, na época, recursos tecnológicos adequados para a realização

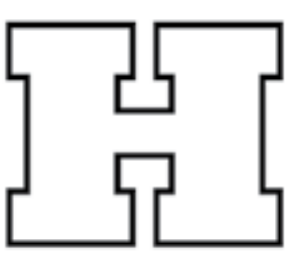

do projeto, que acabou não sendo concretizado.

A cidade captada como paisagem sonora, retransmitida através da emissão radiofônica, situa o rádio na poética de Cage além de um mero veículo de comunicação _ medium. O rádio é também circuito, rede que reconfigura o espaço e o tempo nas sociedades contemporâneas, conectando lugares e tempos na nova aldeia global. É meio poético, que permite a experiência de uma linguagem que não quer significar, mas tão somente soar e recriar. Desmilitarização da linguagem. Soundsense.

“A partitura original (...) consistia em uma espécie de catálogo dos ruídos da cidade, considerados como elementos musicais em si mesmos e não apenas como efeitos sonoros." (BOSSEUR, 1993, p. 16)

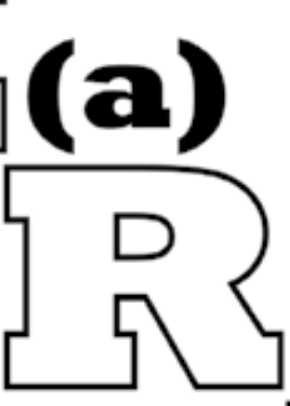

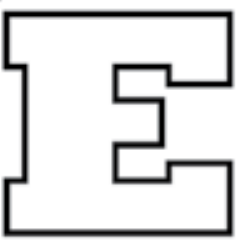

“O que nós precisamos, em Joyce e em nossas vidas, é arriscar, o mais que pudermos, voltar à poesia e ao caos, em vez de ficar sempre do lado seguro, junto do policial."(CAGE, 1992, p.38) 
Cage propõe em Roaratorio uma vez mais a audição do silêncio, experiência para ele renovadora e ao mesmo tempo apaziguadora, por acolher amorosamente (pitY) os opostos: som e ruído, vida e morte. Laughtears. E conclui texto e música aproximando, no último mesóstico, as palavras silêncio e paz.

\section{Just a whisk Of pitY a Cloud in pEace and silence}




\section{Notas}

1 Grifos da autora.

2 Cage refere-se aqui à experiência que realizou no interior de uma câmara anecoica, na qual, isolado de todo ruído exterior, ouviu dois sons: um agudo, seu sistema nervoso em funcionamento, o outro grave, sua circulação sanguínea.

3 Trechos extraídos da entrevista concedida por John Cage ao cineasta Miroslav Sebestik em Nova York, em 2/4/1991, para o documentário Écoute, lançado em 1992.

4 As fotos desta e da próxima página, de autor desconhecido, pertencem aos arquivos do Getty Research Institute, em Los Angeles. 5 Falas extraídas do vídeo documentário da performance de Speech Radio 5 (1955), realizada por John Cage em 1982, com aparticipação de Merce Cunningham.

6 Palavras proferidas pelo júri que concedeu a Cage o Karl-Sczuka-Prize pela melhor composição de 1979, por ter ampliado as fronteiras do rádio como meio.

7 Roaratorio resultou de um convite feito a John Cage por Klaus Schöning para escrever uma música que acompanhasse a leitura de seu texto Writing for the Second Time through Finnegans Wake. A obra foi realizada nos estúdios do IRCAM em Paris, em 1979, para as rádios WDR de Colônia, KRO de Hilversum e SDR de Stuttgart.Engenheiro de som: John David Fullemann.

8 Desse trabalho resultou o texto Listing through Finnegans Wake, com cerca de quatro mil itens.

9 Cage baseou-se, para isso, no livro A Finnegans Wake Gazeteer, de Louis Mink, que lista os lugares mencionados por Joyce em Finnegans Wake.

10 Os mesósticos formam o texto Writing for the Second Time through Finnegans Wake, que serve de base para Roaratorio.

\section{Referências}

BOSSEUR, Jean-Yves. John Cage. Paris: Minerve, 1993.

CAGE, John. Cage on Roaratorio. In: Encarte do CD John Cage Roaratorio. New York: Mode 28/29, 1. ed. 1992, pp.1-8. Collecting the sounds. In: Encarte do CD John Cage Roaratorio. New York: Mode 28/29, 1. ed. 1992, p. 69. Silence. Middletown, Connecticut: Wesleyan University Press, 1973.

CAGE, John \& SCHÖNING, Klaus. Laughtears_Conversation on Roaratorio. In: Encarte do CD John Cage Roaratorio. New York: Mode 28/29, 1. ed. 1992, pp. 28-58.

HOLZAEPFEL, John. David Tudor, John Cage and Comparative Indeterminacy. In: Leonardo Music Journal, Vol. 14, 2004. Cambridge, MA: MIT Press.

TAN, Margaret Leng. Silent Revolution. Andante, 2002. Disponível em: http://users.skynet.be/P-ART/PARADISE/JOURNAL/JOURNL10/ silentrevolution.htm Acesso em: nov. 2009.

\section{Discografia}

CAGE, John. John Cage Roaratorio. New York: Mode 28/29, 1.ed. 1992.

\section{Vídeos on-line}

CAGE, John. John Cage Speech Radio 5, 1982. Disponível em: ttp://www.youtube.com/watch?v=IC6h1A6TEIE\&mode=related\&sear $\mathrm{ch}=$ Acesso em: nov. 2009.

SEBESTIK, Miroslav. John Cage - in Love with another sound - 01. In: Écoute, 1992. Documentário. Disponível em: https://www.youtube.com/watch?v=2aYT1Pwp30M\&mode=related\&search Acesso em: nov. 2009. 